\title{
Features of Display of Anxiety of Children Suffering from Psychosomatic Diseases
}

\author{
Mykola Didukh $^{1 *}$, Iryna Savenkova ${ }^{1}$, Olena Kuznetsova ${ }^{1}$, Iryna Litvinenko ${ }^{1}$, Olesya Oleksyuk ${ }^{2}$ \\ ${ }^{1}$ Department of Psychology, Sukhomlynskyi Mykoaiv National University, Nikolaev, Ukraine \\ ${ }^{2}$ Department of Philogical, Sukhomlynskyi Mykoaiv National University, Nikolaev, Ukraine
}

Received: 18/02/2019

Accepted: 27/09/2020

Published: 20/12/2020

\begin{abstract}
The purpose of the study is to substantiate the individually predetermined patterns and mechanisms of time spent by children suffering from chronic non-communicable diseases of the cardiovascular system, and to identify the level of anxiety of such patients. Method: the $\tau$-type was determined for each patient by the method of chronometric test, for which the classical method of reproduction of intervals of duration to $=2,3,4,5 \mathrm{~s}$, set by the experimenter and reproduced by the electronic chronoscope with accuracy up to 0.001 , was used. with. Studies of the level and form of anxiety in CVD patients have shown that individuals in the experimental sample are characterized by high levels of anxiety. At the same time, it is appropriate to emphasize that the individuals of the sangvidoid group are dominated by the reactive form of anxiety and the melancholoid - by the personal one. The levels of anxiety are consistent with the duration of the biological cycle of CVD patients. The maximum expressiveness of the level of anxiety of patients not only coincides with the end of a quarter of long cycles and their ends, but also begins to recur with a period of 1/4 C, 1/2 C, 1/16 C, 3/4 C.
\end{abstract}

Keywords: Subjective time unit of the individual, Subjective perception of time, Chronopsychological prognosing

\section{Introduction}

Our previous studies emphasize that the legacy of Hippocrates is far from the exhaustion [1 - 4]. It happened historically that his basic idea of psychosomatic unity as the main factor of temperament was vulgarly distorted. It is understood that this brilliant thinker allegedly divided people into four types by the criterion of the predominant fluid in the body. In essence, he, having extensive experience in monitoring patients, identified four types of temperament on the basis of "prevalent" disease [5]. In "Lectures on the History of Medicine" Professor F. Borodulin gives the view of Guppocrates on the redistribution of typical diseases [6]. According to the last, cholerics suffer from their diseases, and phlegmatics suffer from the opposite ones [6]. That is why in Hippocrates' scheme these types are opposite. He further emphasizes that sanguines suffer from their illnesses, but for the manifestation of the flow of a disease the last are close to cholerics. Melancholics are sick with their illnesses, and their manifestation is similar to the picture of signs of the disease of phlegmatic patients. In fact, there was a linear scheme of types of temperament of Hippocrates, who believed that typical "prevalent" diseases are due to the composition of the psyche of the individual. But, being a materialist in his own outlook, he said that this psychic composition depends on the predominance of one of the four fluids (the material base) in his body.

On the other hand, according to Hippocrates, this predominance determines the "prevalent" disease. Therefore, the essence of the idea of the existence of four types with their "prevalent" diseases is that the signs of a disease in its original forms can be detected in healthy individuals of these groups and long before its manifestation in clinical form, as confirmed by studies G. Desai [7], S.Chaturvedi [7], P. Fink [8]. Doctors, treating patients, indicate that each patient has a subjective perception of the disease, which significantly affects its objective (physical) condition.In this analytical section, we only note that there is a bilateral, but the unified character of psychosomatic relations with the transition psychogenic in somatogenic and Vice versa [9]. Considering these relationships in dynamics, such a transition is natural.

Diseases such as «NCDs " include liver disease, gall bladder, cardiovascular disease, kidney and reproductive system diseases, stomach and intestines, respiratory system. According to WHO, cardiovascular disease (CVD) is at the forefront of the NCDs. A third of the planet's adult population suffers from them.They are the cause of every second death, every third disability. Therefore, the attention of doctors around the world is riveted on the problem of CVD. Together with psychologists, they conduct research to remove "risk factors" that allegedly lead to cardiac catastrophes (myocardial infarction). There are about thirty such factors, including wellknown constitutional (overweight, obesity), visceral (hypertension), behavioral (smoking, competitiveness, haste), and typological differences (often latent aggression, increased or high anxiety). Despite the detailed study of "risk factors", scientists have come to the conclusion that they can explain only half of cases of coronary heart disease (CHD) or its clinical form - heart attack $[10,11]$. Therefore, an important point in the prevention of cardiovascular diseases is the consideration of psychological aspects of prevention of these diseases, the consideration of which were engaged Z. Naderi, S. Gholamzaden, L. Zarshenas, and A. Ebadi [12].

Returning to the "risk factors", it is not difficult to understand that they all form a psychosomatic unity. Let's say we take such a psychic component of temperament as high anxiety. The ambiguity and semantic ambiguity of this term in

Corresponding author: Mykola Didukh, Department of Psychology, Sukhomlynskyi Mykoaiv National University,

Nikolaev, Ukraine. E-mail: mykola.didukh@tm.org.ua 
psychology is the consequence of its use in various meanings. It is a hypothetical "intermediate variable" and a temporary mental state that arises under the influence of stressors; and frustration of social needs; and the personality trait that encompasses internal factors and external characteristics; and a motivational component. And above all, it is the psychic component of temperament.

Anxiety is known as an emotional state of acute internal anxiety associated with the prediction of danger; the experience that arises when a person is threatened as a social subject, when their values, their self-perception, and position in society are endangered [13]; at the same time, it is a particularly severe uncomfortable feeling, which most often, though not necessarily, is perceived as the expectation of a threat, a loss, and is often specified in the imagination [13].

In the writings of I. Savenkova, M. Didukh, N. Ruda, N. Hazratova proved that individuals of the sanguine and melancholic group which occupy places at the ends of the typological groups of the continuous spectrum of " $\tau$-types" are characterized by high anxiety, as well as some of the persons of the choleric group who are at its beginning [14]. Physicians are also aware that there are individuals with hypertensive and hypotonic tendencies in the nature of the human population regarding blood pressure. Given that every third adult on the planet suffers from CVD, and "risk factors" explain the disease only in every eighth, you can try to check the location of such patients in typological groups. It is enough to use your own unit $(\tau)$ as an indicator of belonging to a typological group.

Our approach to the study of the etiology, pathogenesis and clinical manifestations of the disease is carried out from a new position, which fully takes into account the laws of time experience $[15,16]$. Based on the $\tau$-type, which determines the individual's unit of time of each individual, it is possible to assign a particular subject to a group with his or her dominant disease (first of all NCDs) with great precision.At the same time, the issues of localization of symptoms of each nosological form of NCDs of organs of the cardiovascular system in the typological group of the continuous spectrum of " $\tau$-types" and the level of anxiety in children suffering from similar diseases. The purpose of the study is to substantiate the individually predetermined patterns and mechanisms of time spent by children suffering from chronic non-communicable diseases of the cardiovascular system, and to identify the level of anxiety of such patients. Objectives of the study: 1) to allocate in duration its own unit of time of an individual suffering from NCDs organs of the cardiovascular system; 2) to compare the duration of one's own unit of time with the psychosomatics of NCDs of the organs of the cardiovascular system of children; and 3) to investigate the level of anxiety of somatic patients with cardiovascular disorders and compare it with the duration of their own unit of time.

\section{Materials and Methods}

The problem of displaying anxiety in patients with chronic CVD is far from being complete resolved, because of the differentiation of forms of anxiety expression in typological groups, depending on the clinical form of CVD, has not been performed so far. At the same time, the issues of consistency of the form and level of anxiety with the duration of the biological cycle of an individual's life in a contingent of children suffering from chronic non-infectious myocarditis of those vegetative-vascular dystonias remain open.

Presentation of the material of the main research and the obtained scientific results. Our task - to investigate in children the localization of symptoms of chronic CVD in typological groups - it was solved experimentally in a contingent of children aged 7 to 14 years, suffering from cardiac NCDs and were treated at the children's hospital and its outpatient department.In other words, the study was conducted with children during both exacerbation and convalescence (recovery) and remission (attenuation) of the disease. The experimentation was performed in three stages. The first questionnaire was filled out for each subject, which revealed the following: the age of the child (indicating the number of years and months at the time of the survey); number, month, year of birth, type of NCD. In the second case, the $\tau$-type was determined for each patient by the method of chronometric test $(10,14,16)$, for which the classical method of reproduction of intervals of duration to $=2,3,4,5 \mathrm{~s}$, set by the experimenter and reproduced by the electronic chronoscope with accuracy up to 0.001 , was used. with. In this case, each patient was offered to reproduce the duration he experienced and limited to two signals - the beginning and the end. These signals were a click that occurs when the chroscope is switched on and stopped. The subject reproduced the intervals that were set on this chronoscope.

Playback every time interval was repeated five times and then the average of each child's own time unit was calculated. The next step in the study was to calculate the duration of the biological cycle of each individual patient. The task was to investigate the manifestation of the C-metric during NCD at different periods of illness (exacerbation, convalescence, and remission). By the law of experiencing an individual's own time [16] its large biological cycle was determined by the formula:

$\mathrm{C}=8.5 \tau$ (years)

where $\tau$ - the individual unit of time of the individual, acting as a "step", which measures the flow of time of his life from birth. In the third stage, the form of manifestation and the level of anxiety in somatic patients with CVD were studied, and then the results were compared with the value of their own time unit and the duration of their biological life cycle. Psychodiagnostic tools were presented by the following methods: Ch. Spielberg, Y.A.Hanina "The scale of assessment of the level of reactive and personal anxiety", G. Eysenko test questionnaire (for teens).

\section{Results}

Investigating one of the "prevalent" diseases of the cardiovascular system, we are convinced that a disease such as myocarditis is localized within its typological group. Significantly, it includes individuals of the sanguine group, that is, individuals, in the body of which, according to Hippocrates, blood prevails. According to the indicators of the Eysenck test, they have a high level of excitation and inhibition, which balance each other. In the behavior of the children of this group are different cheerfulness, optimism, great mobility. Therefore, they approach the "purely" sanguine.

A large group is formed by diseased children with vegetative-vascular dystonia (VVD), which ranks first in the incidence of cardiovascular pathology in childhood. The course of this disease can be realized by hypotonic type. The first type of sick children with VVD were examined. The results of this study showed that the own unit of time in these children is two ranges of intervals: $0.7 \mathrm{~s} \leq \tau<0.8$ s ( 15 patients) and $0.1 \mathrm{~s}<\tau \leq 1.1 \mathrm{~s}$ ( 8 patients), which corresponds to the choleric and phlegmatic groups of individuals in the typological groups of the continuous spectrum of $\tau$-types. At the same time, in the ranges: $0,8 \mathrm{~s} \leq \tau \leq 0,86 \mathrm{~s}$ ( 21 children) and $0,94 \mathrm{~s} \leq \tau \leq 1,0 \mathrm{~s}$ (18 patients), there is a unit of time in children suffering from hypertensive type of VVD. 
Comparing these distributions, it is not difficult to be convinced that patients with hypertensive type VVD have their own unit of time in those areas where healthy " $\tau$-types" have hypertension [6]. The sick children with VVD clearly identified two boundaries $(\tau=0.8 \mathrm{~s}$ and $\tau=1.0 \mathrm{~s})$, in a continuous spectrum of $\tau$-types, in which there is a abrupt transition from a hypotonic tendency to a hypertensive one.

Vegetative-vascular dystonia by hypertonic type defined the boundaries of both groups "purely" by sanguine and "purely" melancholic. Therefore, children who have the same form of "prevalent" disease have differences in psychological contentcharacter. The clinical interview method revealed that one group of children complained of a constant lack of time when doing any work. These are individuals with their own unit of time in the range $0.8 \mathrm{~s} \leq \tau \leq 0.86 \mathrm{~s}$, that is, a sanguine group of individuals. Another group of children with their own time unit in the range of $0.94 \mathrm{~s} \leq \tau \leq 1.0 \mathrm{~s}$ do not experience a time deficit when performing cases, that is, a melancholy group of patients. This again confirms the correspondence of typological groups and dominant diseases in the continuous spectrum of $\tau$-types on the contingent of children aged 7 to 14 years.

These results of an empirical study of patients with myocarditis and vegetative-vascular dystonia were subjected to statistical processing of age data. For each group, the mean age, calculated from the date of birth to the onset of the disease, indicating the large biological cycle and translated into years, was calculated. Estimated and statistical summer-years of the examined children with myocarditis and vegetative-vascular dystonia in the period of exacerbation of the disease are summarized in Tables 1 and 2 .

Comparison of the calculation and statistical years shows that in patients with cardiovascular disease the exacerbation begins at the age, which for this contingent of persons is determined by the fractional number of large biological cycles survived, and the exacerbation of the disease coincides with the end of $13 \frac{13}{4} \mathrm{C}$ (years by cycles $8.6 ; 8.9 ; 9.1$ ); $1 \frac{1 / 2}{2}$ (years by cycles $10.4 ; 10.7 ; 10.9) ; 13 \frac{3}{4} \mathrm{C}($ years by cycles: $12.1 ; 12.4$; 12.8).

\section{Discussion}

By measuring this unit in postinfarction (those who suffered a heart attack) individuals, B. Tsukanov obtained places of their localization within four typological groups [16]. This means that post-infarction patients are localized in their temperament properties within two typological groups sanguine and melancholy. It should be noted that the postinfarctioners themselves have allegedly drawn the boundary lines between the choleric and the sanguine and between the melancholic and phlegmatic groups [17]. This allowed B.Tsukanov argue that coronary heart disease and its clinical form are localized within only two typological groups and do not go beyond them [16].

Looking at the localization of the diseases within the four typological groups, one should not fail to express admiration for the "Greek genius" of Hippocrates [5]. Recall that "chole" is the moisture produced by the liver, and accumulates the gallbladder. These organs are also subject to chronic disease of individuals of the choleric group. Remember, "sanguinis" is a moisture that is constantly distilled by the heart. In persons of sanguine group recorded severe myocardial infarction. "Melana chole" is black bile because it is mixed with blood. Hippocrates said that melancholics are in the most disadvantaged state, because they suffer from diseases of both choleric, and sanguine, and phlegmatic.Indeed, in fact, given the sensitivity of the melancholic, you can agree with the type that "it all hurts." But not for nothing Hippocrates saw the "black bile" of this type, because next to heart attacks [which, incidentally, often smaller], a high jump in blood pressure leads to rupture of the vessels of the brain, called stroke [17].

Table 1: Phases of exacerbation of cardiovascular disease in children (myocarditis)

\begin{tabular}{|c|c|c|c|c|c|c|}
\hline \multirow{2}{*}{ Group } & \multirow{2}{*}{$\tau$-types, $s$} & \multirow{2}{*}{$\mathrm{C}$} & \multicolumn{3}{|c|}{ Cycles (in years) } & \multirow{2}{*}{$\begin{array}{l}\text { Statistical age } \\
\text { of patients }\end{array}$} \\
\hline & & & $1 \frac{1 / 4 \mathrm{C}}{}$ & $1 \frac{1 / 2 C}{}$ & $13 / 4 \mathrm{C}$ & \\
\hline Children (9 patients) & $0,8 \leq \tau \leq 0,82$ & 6.85 & 8.6 & 10.2 & 11.9 & $8-10-12$ \\
\hline Children ( 6 patients) & $0,83 \leq \tau \leq 0,84$ & 7.1 & 8.9 & 10.7 & 12.4 & $8-10-12$ \\
\hline Children (4 patients) & $0,85 \leq \tau \leq 0,86$ & 7.3 & 9.1 & 10.9 & 12.8 & $9-11-13$ \\
\hline
\end{tabular}

Table 2: Phases of exacerbation of cardiovascular disorders in children (VVD)

\begin{tabular}{lllllll}
\hline Group & \multirow{2}{*}{-types, $\mathrm{s}$} & $\mathrm{C}$ & \multicolumn{2}{c}{ Cycles (in years) } & \multicolumn{1}{c}{$\begin{array}{l}\text { Statistical age } \\
\text { of patients }\end{array}$} \\
\hline Children (4 patients) & $0,7 \leq \tau \leq 0,72$ & 6.0 & 7.5 & 9 & 10.5 & $7-9-11$ \\
\hline Children (3 patients) & $0,73 \leq \tau \leq 0,75$ & 6.29 & 7.8 & 9.4 & 11.2 & $7-9-11$ \\
\hline Children (8 patients) & $0,76 \leq \tau \leq 0,79$ & 6.64 & 8.3 & 10 & 11.6 & $8-10-12$ \\
\hline Children (5 patients) & $0,8 \leq \tau \leq 0,83$ & 6.9 & 8.6 & 10.3 & 12.1 & $9-11-12$ \\
\hline Children (3 patients) & $0,84 \leq \tau \leq 0,86$ & 7.2 & 9 & 10.8 & 12.6 & $9-11-13$ \\
\hline Children (16 patients) & $0,94 \leq \tau \leq 0,97$ & 8.1 & 10.1 & 12.2 & 14.2 & $10-12-14$ \\
\hline Children (15 patients) & $0,98 \leq \tau \leq 1.0$ & 8.4 & 10.5 & 12.6 & 14.7 & $10-12-14$ \\
\hline Children (8 patients) & $1.0 \leq \tau \leq 1.1$ & 9.35 & 11.6 & 14.0 & 16.3 & $11-14-16$ \\
\hline
\end{tabular}


"Phlegma" - transparent mucus, which is very much in the stomach of a person, so the stomach phlegmatic is the most vulnerable, and ulcers are very complex. In the zone of "equilibrium" type, kidney and genital diseases are localized. The comparison given above completely confirms Hippocrates' profound rightness. In each type, he saw psychosomatic unity with the locus minoris resistentiae, which for each type is the most vulnerable at a certain age, which is related to the life cycle of the individual's life cycle [10]. It is interesting to compare the distribution of chronic diseases by typological groups with the ancient views of Tibetan medicine. Here is a poem by L.D. Olzoeva [18 ] outlining these views:

"Our feelings build our health.

If you are afraid

You prepare yourself kidney disease.

If you feel angry

Your liver and gall bladder will suffer.

The sadness and oppression of the Spirit darkens

The heart and mind with the disease.

Pride, ignorance, passion, envy and anger -

These feelings (if you have them)

They will strike you mercilessly.

Be your friend.

Become the best doctor yourself.

Find the cause of your illness in yourself".

The poetic form shows the differentiation of the places of least resistance in individuals, taking into account the basic emotional coloring of their behavior. Çoban $\mathrm{H}$. spoke about central or leading emotional coloring characteristic of representatives of different typological groups (19). Indeed, anger and wrath are prevalent in individuals in the choleric group, which has been noted by Tibetan doctors as a sign of liver disease. "Compression of the spirit" as a special emotional state is peculiar to anxious persons, and such are the representatives of the sanguine and melancholic groups in which heart diseases are manifested. Sadness is characteristic of melancholic people who have strokes as a gloomy mind. Situational fear within "here and now" behavior occurs in "equilibrium" individuals. And it is not the fear of a melancholic, which sometimes becomes a personal trait (cowardice), but the fear of "caution without cowardice". That is why Tibetan doctors saw in the form of manifestation of such a fear the cause of kidney disease, which is confirmed by the differential method in the "balanced" features [1].

Comparison shows that the ancient study of Hippocrates and the ancient experience of Tibetan medicine recorded a clear localization of "prevalent" diseases in individuals by their belonging to their typological groups [17]. And it is necessary to pay tribute to this experience, because it focuses a special holistic vision of the psychosomatic unity of the body and human psyche.

\section{Conclusions}

1. The results of the study of patients with cardiovascular system showed that the own time unit of patients with noninfectious myocarditis is in the range of $0.8 \mathrm{~s} \leq \tau \leq 0.86 \mathrm{~s}$, which corresponds to the group of persons in whom "CVDs" in hypertension type "predominate" typological groups in a continuous sector of $\tau$-types. And the own unit of time in children suffering from vegetative-vascular dystonia in hypotonic type is two ranges $-0.7 \mathrm{~s} \leq \tau<0.8 \mathrm{~s}$ (and $0.1 \mathrm{~s}<\tau \leq 1.1 \mathrm{~s}$, which corresponds to the choleric and phlegmatic groups of persons in typological groups of continuous spectrum $(\tau$ types)". In the ranges $0,8 s \leq \tau \leq 0,86 \mathrm{~s}$ and $0,94 \mathrm{~s} \leq \tau \leq 1,0$ find their own unit of time in children suffering from hypertensive type. Sick children with VVD clearly defined two boundaries $(\tau=$ $0.8 \mathrm{~s}$ and $\tau=1.0 \mathrm{~s}$ ), in a continuous spectrum of " $\tau$-types", in which there is a abrupt transition from the hypotonic tendency to hypertonic.

2. Analysis of the age of patients with chronic noncommunicable diseases from the date of birth to the onset of the disease shows that the place of least resistance is most affected at the end of a long large biological cycle or their long quarters. By following the "C-periodicity" of diseases, we can say that in the life of an individual there are a number of separate age points that must be critical. It is at these points that exacerbation of symptoms of chronic noncommunicable diseases is observed.

3. It is common for most of the surveyed patients with NCDs that the clinical manifestations of the disease not only coincide with the end of a quarter of long cycles and with their ends, but also begin to recur at a frequency of $1 / 4 \mathrm{C}, 1 / 2 \mathrm{C}, 1 /$ $16 \mathrm{C}, 3 / 4 \mathrm{C}$ depending on the type group. The disease is chronic in nature because it is not diagnosed in the early stages of ontogenesis.

4. Studies of the level and form of anxiety in CVD patients have shown that individuals in the experimental sample are characterized by high levels of anxiety. At the same time, it is appropriate to emphasize that the individuals of the sangvidoid group are dominated by the reactive form of anxiety and the melancholoid - by the personal one.

Finally, let us note that the individual's belonging to a typological group is a naturally conditioned (innate) property. In this case, knowing one's own means is also knowing the place of the least resistance in one's body, which under certain conditions may become most vulnerable. But does this imply the doom and fatal inevitability of the disease of the system that is the place of least resistance? It doesn't, because knowing the weak point is the key to a vague notion that is called "healthy lifestyles." It is the knowledge of personality that makes it possible to build such an attitude towards one's own organism in order to prevent disorders and breakages in the places of least resistance. "Become a doctor yourself!" On the other hand, knowledge of the body's weak point opens the door to doctors the key to effective prevention and prevention of CVDs. Therefore, it should be emphasized that health care is a task that can be successfully accomplished within the framework of common psychological and medical technologies, using the scientific heritage of medical psychology, primarily experimental content.

\section{References}

[1] Savenkova I, Didukh M, Litvinenko I, Mukhina L. Lange biological cycle duration in patients with respiratoryorgans disorders. Eur J Gen Med.2018;15(6):em83. https://doi.org/10.29333/ejgm/99826

[2] Savenkova I, Didukh M, Litvinenko I., Chuhueva I. Time Factor in Psychological Profiling of Information Technology Specialists for Future Career Success. J. Environ. Treat. Tech. Special Issue on Environment.2019;1:1041-1045.

[3] Savenkova I, Didukh M, Chuhueva I, Litvinenko I. Chronopsychological Mental Development Dysontogenesis Prognosing in Pre-School Children. Eur J Gen Med. 2019;16(2):em110. https://doi.org/10.29333/ejgm/108595

[4] Savenkova I, Shahai M. Dysontogenesis of the Mental Development of Primary school age children from the perspective of the psychology of time. Technologies of Intellect Development.2019;4(25):113-142.

[5] Hippocrates. Philosophizing about Man. Moscow: Medgiz. 1944.

[6] Borodulin FR. Lectures on the History of Medicine. Moscow: Medgiz. 1955.

[7] Desai G, Chaturvedi S. Do Diagnostic Criteria for Psychosomatic Research Explain Diagnosis of Medically Unexplained Somatic Symptoms. Psychotherapy and Psychosomatic.2016;85:121-122. 
[8] Fink P. Syndromes of bodily distress or functional somatic syndromes where are we heading. Journal of Psychosomatic Research.2017;97:127-130. https://doi.org/10.1016/jpsychores2017.04.012 PMid:28606492

[9] Elkelboom EM, Tak LM, Roest AM, Rosmalen JG. A systematic review and meta - analysis of the percentage of revised diagnoses in functional somatic symptoms. Journal of Psychosomatic Research.2016;88:60-67.

[10] Savenkova I, Didukh M, Khazratova N, Snyadanko I. Psychosomatic unity of human from the position of chronopsychology on the example of ischemic disorders and heart diseases. Electronic Journal of General Medicine. 2019;16(6):em157. doi:10.29333/ejgm/114263.

[11]Fava GA, Cosci F, Sonino N. Current Psychosomatic Practice. Psychotherapy and Psychosomatics.2017;86:13-30. https://doi.org/10.1159/000448856 PMid:2788400

[12] Naderi Z, Gholamzadeh S, Zarshenas L, Ebadi A. Psychoemotional Consequences of Hospitalized Elder Abuse from Older Patients' Perspective. Electron J Gen Med. 2020;17(2):em194. https://doi.org/10.29333/ejgm/7811

[13] Tsiring DA, Evstafeeva EA, Ponomareva IV, Sizova YN. Subject and personal particularities of women having various stages of breast cancer. Electron J Gen Med.2019;16(6): em150. https://doi.org/10.29333/ejgm/112266

[14] Savenkova I, Didukh M, Ruda N, Hazratova N. Differentiation of time characteristics in subjects with depressive states. Eur J Gen Med.2019;16(3):em141. https://doi.org/10.29333/ejgm/10-9436

[15]Elkin D. Experiencing time. Doctors thesis. Odessa: ONU imeni I.I. Mecnikova. 1945.

[16] Tsukanov B. Time in human mentality. Odesa: Astroprint;2000.

[17] Ibrayeva AS, Turdalieva BS, Aimbetova GY, Koshimbekov MK, Igissenova AI. Some aspects of the organization of medical and psychological rehabilitation of rescuers in the Republic of Kazakhstan. Electron J Gen Med.2019;16(6): em170. https://doi.org/10.29333/ejgm/115467

[18] Olzoeva LD. Tibetan Medicine Sandalwood Rosary in Lazurite Bowl. Moscow: Medgiz. 1948.

[19]Çoban H, Ediger D. Control of asthma, quality of life, anxiety and depression symptoms among Turkish patients with asthma. Electron J Gen $\quad$ Med.2018;15(5):em71. https://doi.org/10.29333/ejgm/91403 